\title{
NEURONAL FIRING IN THE INFEROTEMPORAL CORTEX OF THE MONKEY IN A VISUAL MEMORY TASK ${ }^{1}$
}

\author{
JOAQUIN M. FUSTER ${ }^{2}$ AND JOHN P. JERVEY \\ Department of Psychiatry and Brain Research Institute, School of Medicine, University of California at Los Angeles, \\ Los Angeles, California 90024
}

Received August 5, 1981; Revised October 26, 1981; Accepted November 6, 1981

\begin{abstract}
The objective of this study was to elucidate the functional role of neurons in the inferotemporal cortex of the primate. Single unit activity was recorded with microelectrodes in monkeys performing a visual delayed matching-to-sample task. On each trial, the animal was exposed briefly to a colorthe sample-and, after a period of delay, had to select the same color among two or four colors simultaneously presented. Thus, correct performance of the task required perception, retention, and recognition of the sample color for every trial. A large number of inferotemporal units were seen to react to the stimuli with changes of firing frequency. Many units showed color-dependent reactions, suggesting their involvement in perception and discrimination of colors. A substantial contingent of cells showed increased, sustained, and in some cases, color-dependent discharge during the delay which was not necessarily preceded or succeeded by firing changes in sample or match periods. It is proposed that those cells were engaged in temporary retention of the sample stimulus. Since most of the inferotemporal units examined showed firing changes in more than one period of a trial, they appeared to be involved in more than one of the operations required by the task. Thus, the data do not support a clear-cut topographic separation of visual functions within the inferotemporal cortex. However, neurons that appear to participate in visual memory, either exclusively or in addition to other functions, are concentrated in the cortex of the lower bank of the superior temporal sulcus.
\end{abstract}

In primates, it has been well demonstrated that the inferior temporal cortex takes part in higher visual functions (see review by Gross, 1973). That cortical region (area TE of Von Bonin and Bailey, 1947) receives input from the peristriate cortex (Jones and Powell, 1970; Rocha-Miranda et al., 1975; Seltzer and Pandya, 1978; Desimone et al., 1980). Inferotemporal (IT) cortex neurons have relatively large visual receptive fields, almost invariably including the fovea, and show selective reactions to such stimulus features as size, shape, contrast, and color (Gross et al., 1972; Desimone and Gross, 1979; Sato et al., 1980). It has long been known that monkeys with IT lesions show a deficit in performance of visual discrimi-

\footnotetext{
' This work was supported by Grant BNS 76-16984 from the National Science Foundation and Grant AA-3513 from the National Institute of Alcohol Abuse and Alcoholism. J. M. F. is the recipient of Research Scientist Award MH 25082 from the National Institute of Mental Health. We wish to thank R. Bauer, W. Bergerson, M. Dunst, L. Holifield, J. Kruse, R. Lindsay, B. Lubell, G. Mount, D. Riley, J. Romano, R. Smith, and J. Thomas for their valuable help in various aspects of this research.

'To whom correspondence should be addressed at Neuropsychiatric Institute/UCLA, 760 Westwood Plaza, Los Angeles, CA 90024.
}

nation tasks (Chow, 1951; Cowey and Gross, 1970; Dean, 1976; Moss et al., 1981). Such a deficit does not seem attributable to a disruption of the sensory aspects of vision but rather of the ability to form and retain associations of visual stimuli with each other and with reinforcement (Gross, 1973).

The present study investigates the activity of the monkey's IT neurons during the performance of a delayed matching-to-sample task. The purpose of the investigation was to determine which facets of visual function IT neurons subserve. That behavioral task is exceptionally well suited for the purpose, because every delayed matching trial requires from the animal the perception, temporary retention, and recognition of a discrete item of visual information. These operations are conveniently bracketed in time, thereby allowing assessment of neuron participation in each of them separately. The rationale for our study is supported by evidence that both permanent and reversible IT lesions cause deficits in delayed matching performance (Kovner and Stamm, 1972; Delacour, 1977; Sahgal and Iversen, 1978; Fuster et al., 1981).

Other studies in monkeys performing visual discrimination tasks (Braitman and Wilson, 1976; Ridley et al., 1977; Gross et al., 1979; Sato et al., 1980; Mikami and 
Kubota, 1980) have demonstrated the feature-dependent reactivity of IT units to the stimuli controlling performance. Furthermore, the reactions of some of the units described in those studies appear to some degree related to such factors as attention and relevance of the stimulus. The present study not only confirms and extends those findings but indicates that neurons in certain parts of IT cortex are most probably engaged in retention of visual information.

\section{Materials and Methods}

Subjects. Seven male macaques (Macaca mulatta) were used in this study. Their weight ranged between 6 and $9 \mathrm{~kg}$. They were housed in individual cages and maintained on an ad libitum diet of chow and, periodically, some fruit. Fluid intake was limited (no water for the $24 \mathrm{hr}$ preceding a testing session).

Behavior. The animals were trained to perform a delayed matching-to-sample (DMS) task with colored stimuli. In the testing apparatus, the subject sat in a primate chair facing a white panel with translucent stimulus-response buttons (each $2.5 \mathrm{~cm}$ in diameter). A trial began with the presentation of the sample, a colored light, in a centrally located button (Fig. 1). The animal turned it off by pressing the button. After a delay, two or four colors, one of them that of the sample, appeared simultaneously in a horizontal row of buttons under the sample button. Pressing the button with the sample color induced automatic delivery of fruit juice (about $1 \mathrm{ml}$ ) to the animal's mouth by way of a metal spigot. Choice of any other color terminated the trial without reward. The sample color and its position in the choice buttons were changed at random from trial to trial. Thus, for a correct response, the animal had to perceive the sample and retain it through the delay. The length of the delay was varied during both training and testing, but for unit recording, it was ordinarily set between 16 and $20 \mathrm{sec}$.

Two of the subjects were trained to perform the task with two colors, red and green, as sample and choice colors. Five others were trained with red, yellow, green, and blue. The color of the buttons was achieved by rear projection of white light through Cinemoid color filters. Intensity and wavelength were measured by means of a Pritchard Spectra photometer. The sample stimulus, whatever the color, had a luminance of $13.5 \mathrm{~cd} / \mathrm{m}^{2}( \pm 0.1$ log unit) and subtended $8^{\circ}$ of visual field. The dominant $\lambda$ was $620 \mathrm{~nm}$ for red, $590 \mathrm{~nm}$ for yellow, $530 \mathrm{~nm}$ for green, and $480 \mathrm{~nm}$ for blue.
It took 3 to 6 months to train an animal to an asymptotic level of performance. Having reached that level, most animals made only occasional errors on trials with a 16 - to 20 -sec delay.

Surgery. Upon completion of behavioral training, the animals were submitted to surgery, under Nembutal anesthesia, for implantation of recording gear. Hollow stainless steel pedestals for a microelectrode positioner were implanted in temporal bone over IT cortex. One of the animals was fitted with periorbital $\mathrm{Ag} / \mathrm{AgCl}$ eye movement recording electrodes (Bond and Ho, 1970). Threaded metal sleeves were embedded in cement, over the skull, for eventual fixation of the head during recording.

Recording. Recording was initiated between 2 and 4 weeks after full recovery from surgery. Before the start of recording sessions, the experimental animal was habituated to behavioral testing with its head fixed. In preparation for a recording session, a hydraulic positioner (Fuster, 1961) with a metal microelectrode was attached to an implanted pedestal for remotely controlled penetration of IT cortex during behavioral testing. Either tungsten or platinum/iridium microelectrodes were used in these experiments, with impedance, at $1000 \mathrm{cps}$, ranging between 0.7 and 3.0 megohms. Input from a microelectrode was led to a capacity-coupled amplifier with matching input impedance and monitored acoustically and with an oscilloscope. Ordinarily, the animal was submitted to a series of DMS trials with short delays (6 to $10 \mathrm{sec}$ ), while the microelectrode was advanced slowly in search of single unit activity. As soon as the extracellularly recorded spikes from a single unit were picked up, the movement of the microelectrode was halted and its depth was noted on the micrometric scale of the hydraulic system controlling its advance. The possible relationships then were explored between the firing frequency of the unit and the events of the task. Only those units that showed an apparent correlation, however minor, between firing and one or more events of the trial sequence were selected for recording. As it turned out, the great majority of IT units encountered with the microelectrode fulfilled that broad criterion and were characterized by us as "responsive." After ascertaining the responsiveness, isolation, and stability of a unit, recording was initiated with a multichannel (Ampex FR1200) tape recorder and the animal was subjected to a series of DMS trials with 16- to 20-sec delays. Recorded on one channel was the output of a Schmitt trigger

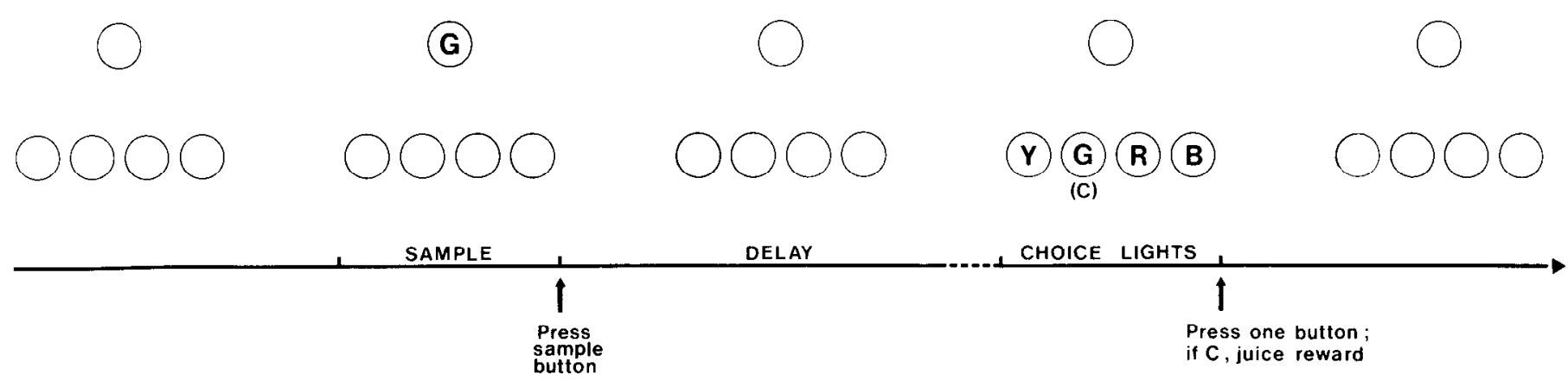

Figure 1. Sequence of events in a delayed matching-to-sample trial (with a green sample light). $G, \mathrm{Green} ; Y$, yellow; $R$, red; $B$, blue; $C$, correct choice light. 
transforming the unit spikes into standard pulses $(0.5$ msec, $1 \mathrm{~V}$ ) for subsequent computer analysis of spike frequency. Two other channels were used for the DCrecorded and amplified vertical and horizontal eye movements. A fourth channel was used for recording a digital code to mark the initiation of trials and DC voltage changes marking the events within them (i.e., onset and offset of the sample light, onset and offset of the choice lights, and juice delivery after correct response trials).

During recording from a given cell, successive trials were presented at intervals of about $50 \mathrm{sec}$ for as long as the unit record remained stable and until data from sufficient trials were collected for analysis. The number of trials varied somewhat from unit to unit, depending on the stability of the record and the frequency and variability of firing. Practically all units analyzed were recorded through at least five trials with each of the sample stimuli of the task. On completion of recording from a given unit, microelectrode advancement was resumed in search of another. Ordinarily, activity from one to three units was recorded in any given session. A session usually lasted about $3 \mathrm{hr}$, and during this time, the animal consumed 100 to $200 \mathrm{ml}$ of fruit juice.

Histology. Upon termination of experiments, small lesions were made in brain tissue at various locations by passing current $(100 \mu \mathrm{A}, 15 \mathrm{sec})$ through small electrodes introduced with the micropositioner. The electrolytic lesions were to serve as reference marks for reconstructing the position of the units recorded. The animals were sacrificed with an overdose of Nembutal and the brain was extracted, fixed in formalin, and coronally cut $(80$ $\mu \mathrm{m}$ ), and the sections were stained by a Nissl method. The stained sections were photographed and the estimated location of all of the registered cells was marked in enlarged $(\times 10)$ pictures.

Analysis. All analysis was done off-line by means of a MINC-11 computer system with graphic capability. The analysis of a single unit's activity proceeded through the following steps: (1) digital conversion of the unit's impulses and the event code with real time reference; (2) average frequency histograms of the unit's activity, timelocked with sample onset, for all trials with each of the sample colors; (3) statistical analysis of firing frequency changes as a function of sample color and trial epoch (sample period, delay period) using as a base line reference the firing of the unit during the $16 \mathrm{sec}$ preceding each trial. Differences from the base line for each of those variables were submitted to $t$ tests using the intertrial variance for computing the error term. The results of this analysis were used for characterizing the reactions of each unit to the events of a DMS trial.

For a few experiments, the electro-oculogram (EOG) was digitized and plotted to determine ocular fixation on DMS stimuli. The EOG was accurate within $5^{\circ}$. Graphic displays of cell discharge were generated using the start of fixation as a reference.

\section{Results}

Data base. The majority of cells selected for study were situated in area TE (Von Bonin and Bailey, 1947), comprising the cortex of the inferior temporal convexity (middle and inferior temporal gyri) and the cortex lining the lower bank of the superior temporal sulcus (Fig. 2). A smaller proportion of the units investigated were situated in the cortex of the upper bank of that sulcus (area TA) and, therefore, not in IT cortex proper; here, they will be generally referred to as "upper bank cells." In addition, cells in deeper structures, such as the caudate nucleus and the hippocampus, also were isolated and studied, but these cells will not be dealt with here. Table I summarizes the data base of the present study. As the table shows, all animals contributed substantially to the sample of IT units, but practically all upper bank units were contributed by one animal.

Spontaneous activity. As previously found in other regions of mammalian cortex (Fuster et al., 1965; Rosenkilde et al., 1981), the spontaneous firing frequency of cells in IT cortex was found to be, on the average, relatively low (median: 3.92 spikes/sec). The distribution of the cells by spontaneous rate shows a wide range of frequencies and marked skewness (Fig. 3). It should be noted that our sample does not include an indeterminate number of very slow units that were unresponsive to the stimuli of the behavioral task and, therefore, did not meet the selection criterion.

Also widely variable were the patterns of spontaneous discharge. Some cells fired continuously and relatively fast, while others showed slow and irregular sequences of spike bursts. In general, cells spontaneously firing continuous streams of spikes were more apt to react to the task stimuli than those firing slowly and in bursts.

Reactions to the sample stimulus. Most cells showed an excitatory reaction to the sample stimulus opening a trial (Table II). The reaction might be brisk or sluggish, but in either case, its latency after stimulus onset was relatively long, over 70 msec. Some cells-more commonly those in the upper bank than those in IT cortexshowed inhibitory reactions to the sample. The duration of the deviation from spontaneous firing varied considerably among cells. In some units, it was confined to the sample period, whereas in others, it extended into the subsequent delay period.

Complex reactions, including both excitation and inhibition, were relatively rare. In such cases, the first component of the reaction determined our typification of the cell. Also rare was the cell that exhibited both on and off reactions to the sample stimulus. However, it was not uncommon for a cell to first show firing deviation from the base line immediately following the termination of the sample presentation, at the beginning of the delay.

In spite of some intertrial variability, any cell could be readily classified into two broad categories, differential or nondifferential, depending on whether it showed statistically different reactions to different sample stimuli. Sample differential cells were found to be much more common in IT cortex than in the cortex of the upper bank (Table II).

Differential cells could be of three types. The most common were characterized by excitatory reactions of different magnitude to different colors. Other units showed reactions to at least one color and none to another, and still others, definitely a minority, showed reciprocal reactions, that is, excitation to one color and inhibition to another. Figure 4 shows an example of the first type. The cell reacts with different degrees of exci- 

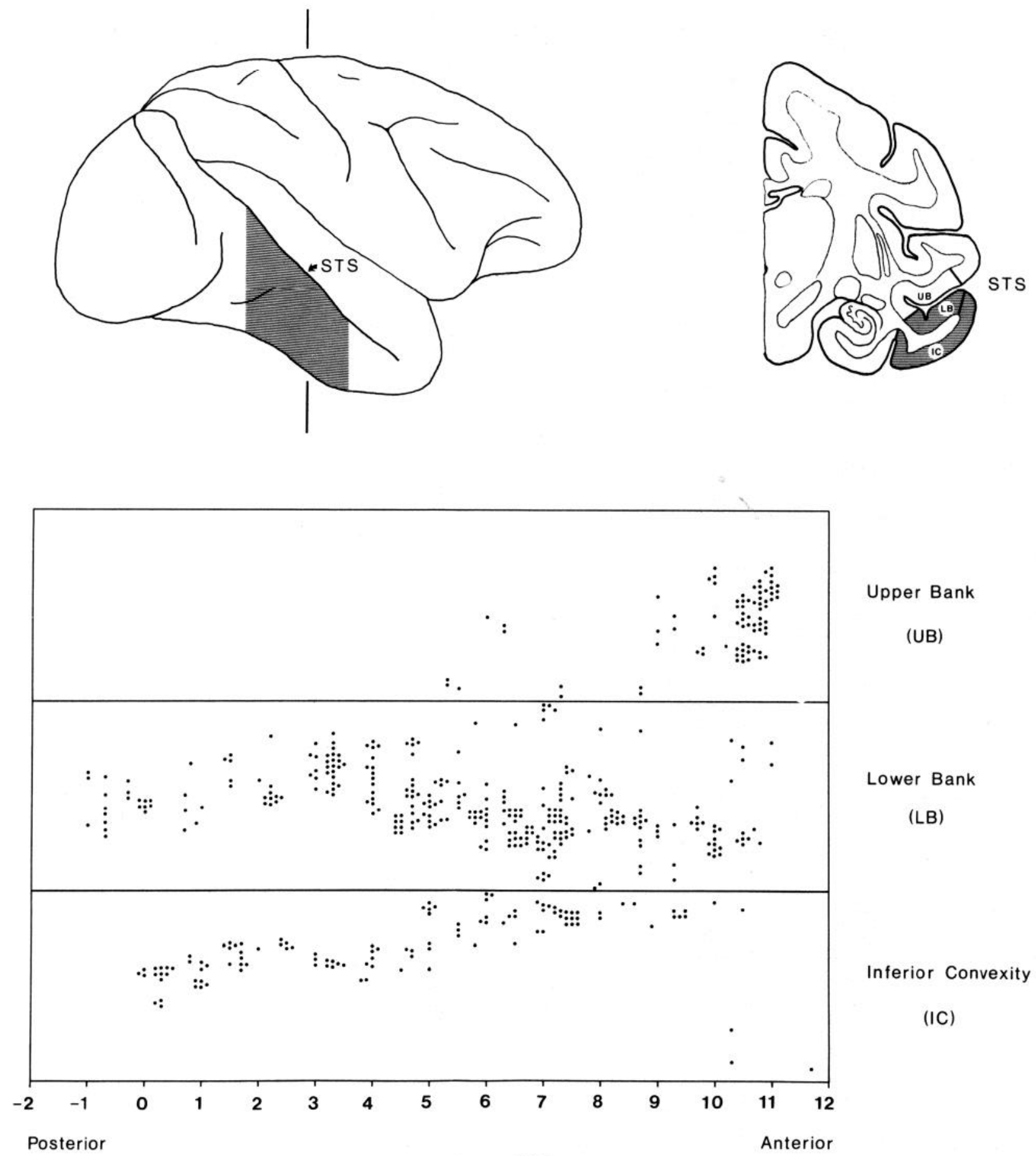

\section{STEREOTAXIC PLANE}

Figure 2. Above, Lateral view and cross-section of the monkey's brain; shading indicates the IT cortical region from which single unit records were obtained. The scatter plot below shows, in a highly schematic diagram of unfolded cortex, the relative position of all of the units constituting the data base of the present study. STS, Superior temporal sulcus.

tation to the four colored samples. Cells tested in fourcolor DMS, such as that one, frequently showed that the response to yellow, whether excitatory or inhibitory, was more similar in magnitude to the response to red than that to blue or green. Conversely, blue and green responses tended to be more similar to one another than to yellow or red responses. Thus, depending on which pair of colors elicited the highest excitatory response, a cell could be characterized as a "warm" or "cold color" cell. Figure 5 displays the reactions to the sample of a cold color cell.

Green and red were the two colors tested on all animals and units. In the area of IT cortex explored, the proportion of cells predominantly activated by the green sample 
TABLE I

Data base

\begin{tabular}{llccccc}
\hline \multirow{2}{*}{ Monkey } & Side & Peneirations & \multicolumn{5}{c}{ Units } \\
\cline { 4 - 7 } & & & $\begin{array}{c}\text { Inferior } \\
\text { Convexity }\end{array}$ & $\begin{array}{c}\text { Lower } \\
\text { Bank }\end{array}$ & $\begin{array}{c}\text { Upper } \\
\text { Bank }\end{array}$ & Total \\
\hline DMS-5 & Right & 15 & 5 & 19 & 0 & 24 \\
DMS-7 & Right & 11 & 4 & 8 & 3 & 15 \\
& Left & 39 & 19 & 68 & 0 & 87 \\
DMS-9 & Right & 51 & 2 & 8 & 62 & 72 \\
& Left & 9 & 3 & 6 & 0 & 9 \\
DMS-11 & Right & 20 & 1 & 25 & 0 & 26 \\
& Left & 20 & 28 & 1 & 0 & 29 \\
DMS-15 & Right & 18 & 13 & 15 & 0 & 28 \\
& Left & 22 & 12 & 16 & 0 & 28 \\
DMS-17 & Right & 32 & 6 & 44 & 4 & 54 \\
& Left & 14 & 0 & 11 & 7 & 18 \\
DMS-21 & Right & 38 & 8 & 45 & 3 & 56 \\
& Left & 35 & 18 & 32 & 0 & 50 \\
& & - & - & - & - & - \\
\multirow{2}{*}{ Total } & & 324 & 119 & 298 & 79 & 496 \\
\hline
\end{tabular}

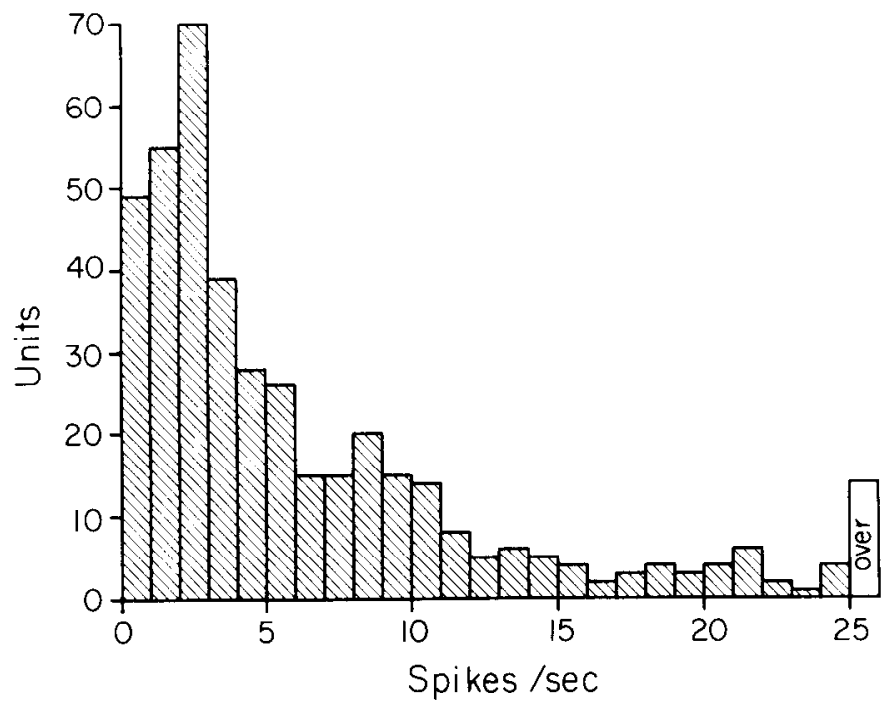

Figure 3. Ranked distribution of the IT units according to the frequency of spontaneous discharge.

was comparable overall to that of cells predominantly activated by the red sample (13 versus $14 \%$ ), although the two proportions varied somewhat for different subareas.

Activity during the delay. More than half of all cells exhibited different frequency of firing during the delay than during the intertrial base line period. About onethird of those in IT cortex showed elevated delay discharge, whereas one-fifth showed depressed delay discharge (Table III). The rest showed either no changes or reciprocal deviations of delay discharge, that is, excitation or inhibition depending on the color of the sample. The ratio of delay-excited to delay-inhibited cells was just about reversed in the upper bank cortex, where the latter were more common than the former and where virtually no delay differential cells were observed.
In general, IT cell activity deviated more from the base line early in the delay than later in that period. Both delay excitation and inhibition tended to diminish in the course of the delay. Some units, however, showed the opposite trend, that is, an enhanced deviation from base line firing frequency as the delay progressed. In any event, the important point is that a large proportion of IT cells manifested persistent deviation from the base line until the very end of the commonly used delays (16 to $20 \mathrm{sec}$ ).

During the delay, $10 \%$ of the IT cells showed differential firing, in other words, a different level of activity depending on the color of the sample for the trial. In most instances, the difference was merely of degree: a cell was significantly more activated or inhibited after one color than after another. However, in some, the difference was one of direction (reciprocal): excitation after one color and inhibition after another.

Some units carried over into the delay the differential firing that they exhibited during the sample period (Fig. 6). However, differential sample activity was not a necessary condition for differentiation during the delay. A cell might show nondifferential reactions or no reaction at all to sample presentation yet show differential firing during the ensuing delay (Fig. 7). Differential activity generally terminated with the end of the trial (Figs. 6, 7, and 8).

Reactions to the choice stimuli. On presentation of the choice lights, at the end of the delay, IT units tended to react in a manner similar to their reaction to the sample. Thus, excitation and inhibition at the sample were followed, respectively, by excitation and inhibition on appearance of the choice lights for the color match, although the reactions to the two events often differed considerably in degree: some units showed little reaction to the sample and much to the choice lights (Fig. 8), while in others, the opposite was true.

The general similarity of reactivity to sample and choice lights applies also to color differentiation. Thus, the selective reactions shown by some units at the sample were observable again at the choice, even though now the sample color was not presented alone but in combi-

TABLE II

Reaction to sample stimulus

All units were classified by their reactions to red and green sample stimuli. Percentages are in parentheses.

\begin{tabular}{|c|c|c|c|c|}
\hline \multirow[b]{2}{*}{ Type } & \multicolumn{4}{|c|}{ Units } \\
\hline & $\begin{array}{c}\text { Inferior } \\
\text { Convexity }\end{array}$ & $\begin{array}{c}\text { Lower } \\
\text { Bank }\end{array}$ & $\begin{array}{l}\text { Upper } \\
\text { Bank }\end{array}$ & Total \\
\hline \multicolumn{5}{|l|}{ Nondifferential } \\
\hline No change & $5(4)$ & $39(13)$ & 3 (4) & 47 \\
\hline Excitation & $47(39)$ & $117(39)$ & $41(52)$ & 205 \\
\hline Inhibition & $24(20)$ & $62(21)$ & $24(31)$ & 110 \\
\hline \multicolumn{5}{|l|}{ Differential } \\
\hline Excitation & $35(30)$ & $73(25)$ & $5 \quad(6)$ & 113 \\
\hline Inhibition & $3(3)$ & $4(1)$ & 1 (1) & 8 \\
\hline Reciprocal $^{a}$ & $5 \quad(4)$ & 3 (1) & $5 \quad(6)$ & 13 \\
\hline Total & $119(100)$ & $298(100)$ & $79(100)$ & 496 \\
\hline
\end{tabular}

"Excitation by one color and inhibition by the other. 


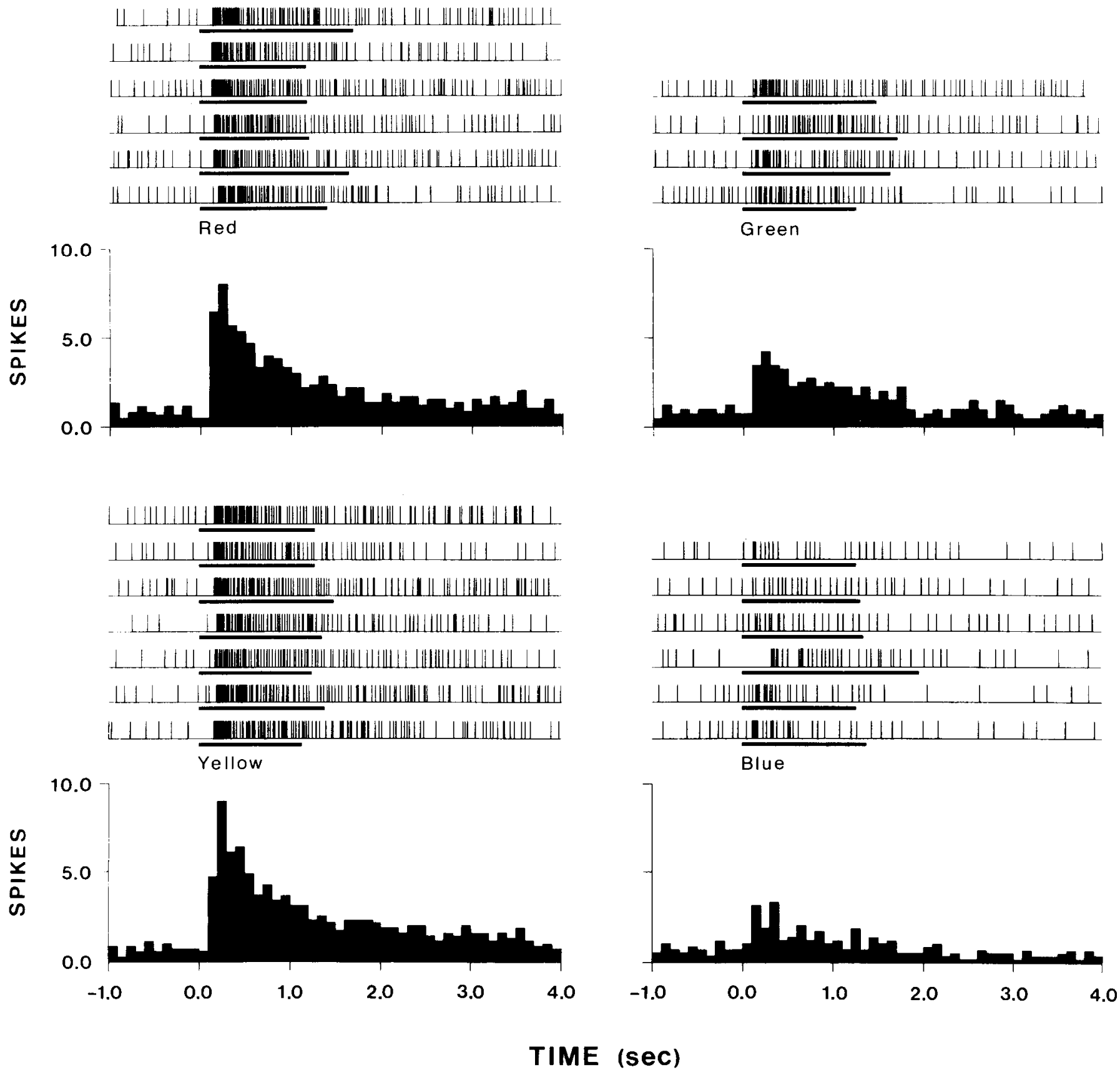

Figure 4. Graphic display of the firing of an IT cell during the sample period (horizontal bars) of DMS trials. Each histogram (time-locked with sample onset) represents the average frequency for the individual records above it, which are grouped by sample color. Bin width, $100 \mathrm{msec}$. The unit shows a preferential reaction to red and yellow.

nation with one or three other colors. For example, if a unit showed a greater excitatory response to the yellow sample than to any other sample, the unit had a tendency to show a greater excitatory response to the presentation of the four choice lights on trials in which yellow was the color of the sample than on trials in which it was not (Fig. 6).

In other words, cell reactions to the sample were, in some respects, "matched" by comparable reactions to the array of choice lights. One simple explanation is that the animal, just before the choice, foveated the sample color for the trial more intently or for a longer time than the other colors by it. However, analysis of the activity of a few selected units in relation to eye movement revealed that foveation of the sample color was not the only factor accounting for differential reactions to the choice lights. Indeed, as the unit in Figure 9 illustrates, the response to the sample color, in some cases, appeared to begin before fixation of the eyes on the button that displayed that color, as if anticipating it.

After the choice, cell activity, as a rule, returned promptly to the base line. This was more remarkable in units that exhibited protracted deviations from that base line during the entirety of the delay or large reactions to 


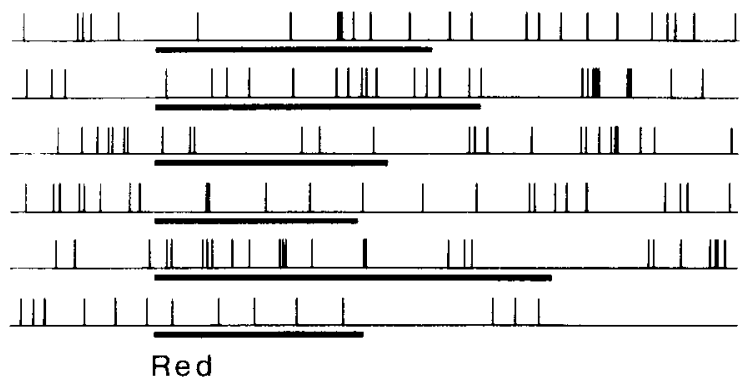
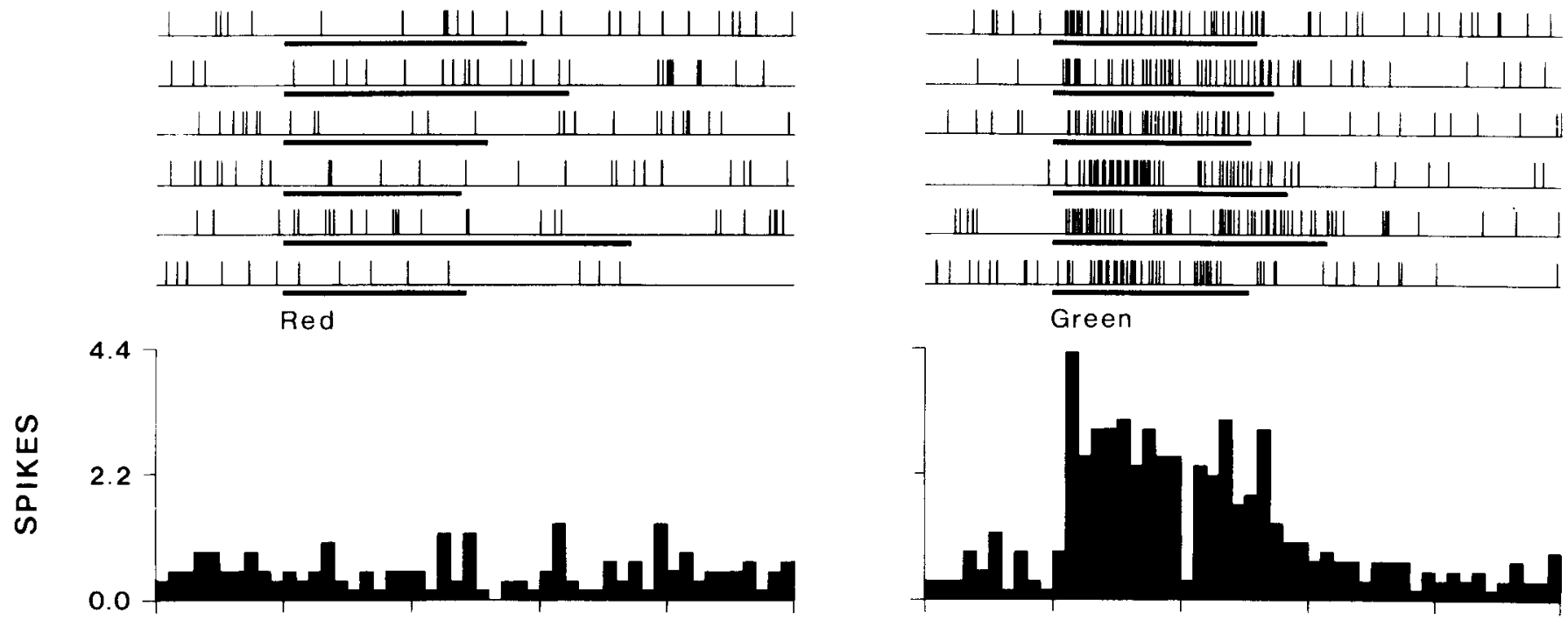

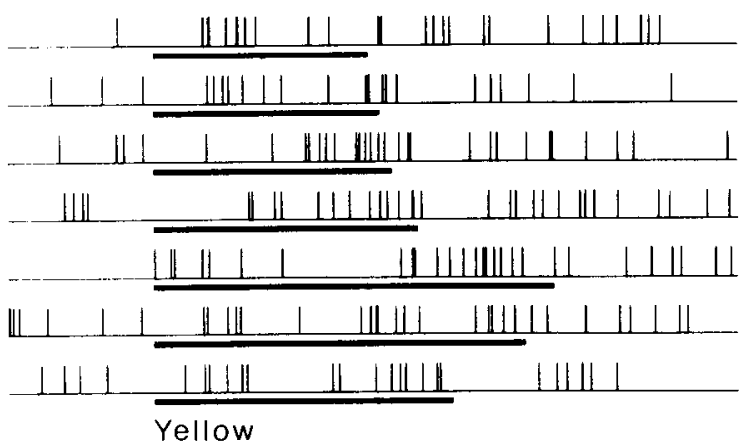
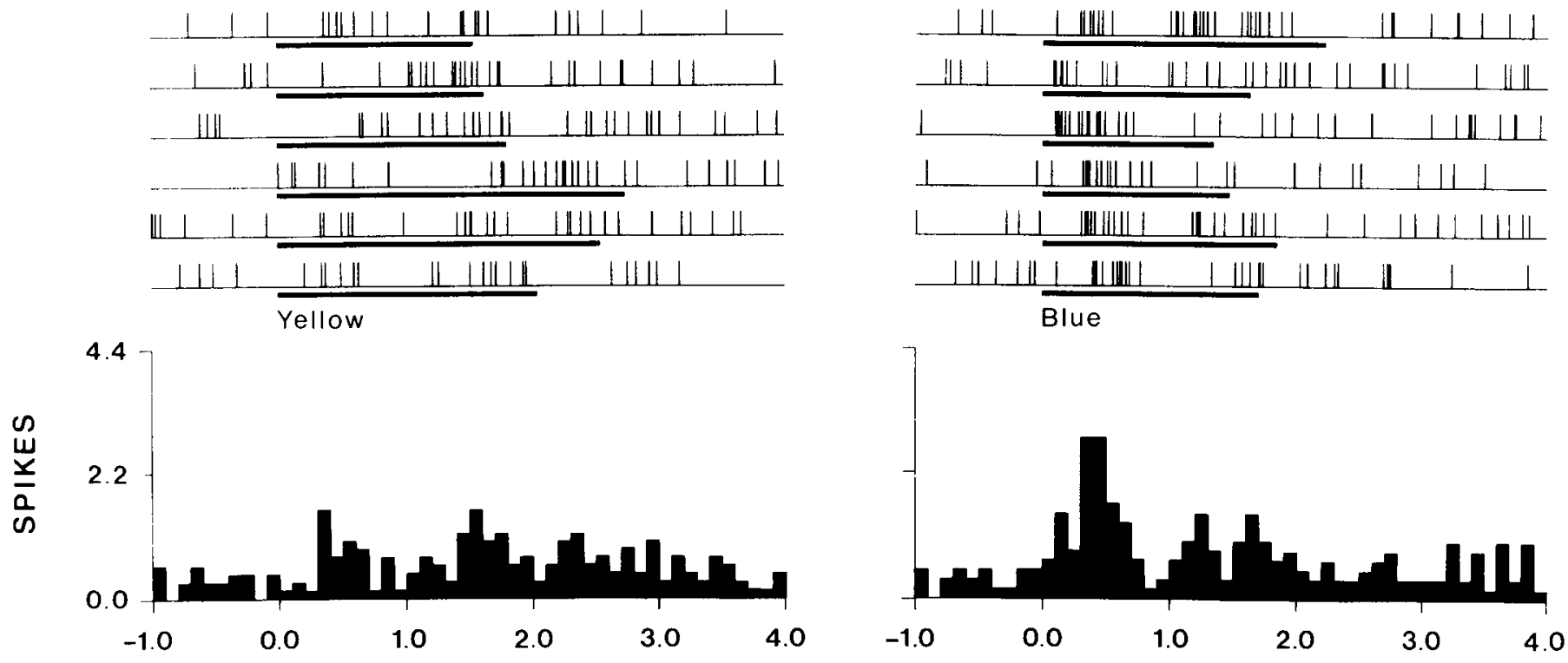

\section{TIME (sec)}

Figure 5. Sample period activity of an IT cell reacting markedly to the green sample and also, though less, to the blue sample.

the choice lights; in many cases, those deviations were of greater magnitude than those to the sample (Figs. 6, 7, and 8).

Relations to performance. In spite of the relatively long delays interposed between the sample and match, the animals committed few errors. Consequently, the appropriate comparison of unit activity between correct and incorrect response trials was usually difficult and rarely revealed statistically significant differences. Nevertheless, during the recording of certain IT units that could be held and tested through an exceptionally long series of trials, a subtle but unmistakable attenuation of cell reactions was observed periodically in correct as well as incorrect response trials. That attenuation, to judge from concomitant increases in behavioral reaction time and incidence of errors, could best be ascribed to lapses of attention or motivation.

Subtle correlations between IT unit activity and performance also could be detected by careful consideration of peculiarities in the behavior of individual monkeys. One animal, for example, showed a tendency to confuse red and yellow in DMS performance; his errors might be attributed to proactive interference (Wilson et al., 1972), since most of them occurred in red sample trials succeeding yellow sample trials or vice versa. In any event, that tendency to confuse red and yellow was reflected by relatively low unit differentiation of those two colors, as compared to green and blue, in the sample and delay 
TABLE III

Activity during the delay

All units were classified by their differences of activity (with respect to intertrial base line) after red and green sample stimuli. Percentages are in parentheses.

\begin{tabular}{|c|c|c|c|c|}
\hline \multirow{2}{*}{ Type } & \multicolumn{4}{|c|}{ Units } \\
\hline & $\begin{array}{l}\text { Inferior } \\
\text { Convexity }\end{array}$ & $\begin{array}{c}\text { Lower } \\
\text { Bank }\end{array}$ & $\begin{array}{l}\text { Upper } \\
\text { Bank }\end{array}$ & Total \\
\hline \multicolumn{5}{|l|}{ Nondifferential } \\
\hline No change & $67(56)$ & $118(39)$ & $39(49)$ & 224 \\
\hline Excitation & $25(21)$ & $88(30)$ & $11(14)$ & 124 \\
\hline Inhibition & $21(18)$ & $57(19)$ & $28(36)$ & 106 \\
\hline \multicolumn{5}{|l|}{ Differential } \\
\hline Excitation & $4 \quad(3)$ & $25 \quad(8)$ & 1 (1) & 30 \\
\hline Inhibition & 1 (1) & $8 \quad(3)$ & $0 \quad(0)$ & 9 \\
\hline Reciprocal $^{a}$ & 1 (1) & 2 (1) & $0 \quad(0)$ & 3 \\
\hline Total & $119(100)$ & $298(100)$ & $79(100)$ & 496 \\
\hline
\end{tabular}

${ }^{a}$ Excitation after one color and inhibition after the other.

periods. By contrast, units in approximately the same region in another animal that rarely confused red and yellow showed marked red-yellow differentiation.

Topographic distribution. Cells showing similar responses to the sample colors or similar forms of colorrelated delay activity were often found in close vicinity of each other. On advancing the microelectrode some 50 to $150 \mu \mathrm{m}$ after completing the recording of a unit, it was not unusual to encounter another unit with like properties; nor was it unusual to find similar units along the same path of penetration, and at the same depth, on separate recording sessions. These observations suggest that cells of common properties were clustered together. However, because of such factors as the difficulty of ensuring orthogonal penetration of the cortex and the limitations of accuracy in the reconstruction of unit positions (particularly in sulcal cortex), il was not pussible to determine precisely the shape and size of the apparent clusters of functionally similar cells.

Nonetheless, at a coarser anatomical level, it was possible to determine that some of the general types of units encountered in our study were not distributed uniformly in IT cortex (Tables II and III). Sample-activated cells, differential or not, were about evenly distributed throughout IT cortex, while delay-activated cells were more common in the cortex of the lower bank of the superior temporal sulcus than in that of the IT convexity $\left(\chi^{2}=6.14 ; p<0.02\right)$. Also more common in the lower bank were delay differential cells $\left(\chi^{2}=3.59 ; p<0.06\right)$. Figure 10 schematically illustrates the topographic distribution of delay-activated cells and delay differential cells.

\section{Discussion}

Color was only one of several attributes of the sample stimulus appearing before the animal at the start of the trial. Other features of that stimulus were its size, its brightness, and the temporal and spatial contrast that it produced in the display panel. In order to test the role of color, those other parameters were made equal for all trials. However, it may be that many of the IT units investigated responded to one or more of those other physical features, which here by design were kept constant from trial to trial and which other experiments have shown to activate IT units (Gross et al., 1972; Desimone and Gross, 1979; Sato et al., 1980). There may lie the explanation for the high proportion of nondifferential (color-independent) sample-activated cells in IT cortex.

Moreover, it is possible that a large number of IT cells were activated not only by physical characteristics of the sample but by internal input deriving from its meaningi.e., association with reward-in the context of the task, another property of that stimulus that may be assumed to be constant across trials and samples. Both behavioral significance and situational variables have been seen to modify the response of IT cells to a visual stimulus (Braitman and Wilson, 1976; Rolls et al., 1977; Gross et al., 1979; Mikami and Kubota, 1980). The modulating role of attention in IT unit responses is examined in another study using a variant of the DMS task (Fuster and Jervey, 1981).

Whatever the role of meaning and attention or visual features other than color in the reaction of IT cells, it is clear that color determined the magnitude and, in some cases, direction (excitation or inhibition) of some reactions. Since color was also the critical factor determining the choices of the animal and their outcome, it is reasonable to conclude that sample differential cells probably took part in the perception and discrimination of the colors guiding the task.

The most salient finding of this study is the presence of a large number of IT cells that exhibited marked deviations from base line firing during the intratrial delay. Among such cells, the most remarkable were those that showed color-dependent activity after the sample color had disappeared.

At least three interpretations of the sustained activation of IT units during the relatively long delay period that followed the sample should be considered. One is that it is a form of sensory afterdischarge elicited by the sample in the geniculostriate system and propagated to IT cortex. Brief visual stimuli, in the acute preparation, have been noted to elicit exceptionally long reactions in some IT units (Gross et al., 1977; C. G. Gross, personal communication). However, the concept of afterdischarge cannot easily be applied to delay activations following little or no reaction to the sample or developing in the course of the delay. Another possible explanation is that, in the interval between the sample presentation and match, the animal was under increased alertness and, in that state, nonspecific input of subcortical origin was responsible for the increased general activity of cortical cells. Such an explanation is inconsistent with the scarcity of delay activation and prevalence of delay inhibition in a cortical area outside of the IT region, namely, the upper bank of the superior temporal sulcus. A third possibility, which cannot be entirely dismissed even in the absence of supporting behavioral or EOG evidence, is that the animals attended more to "background" stimuli during the delay than during the intertrial interval, 


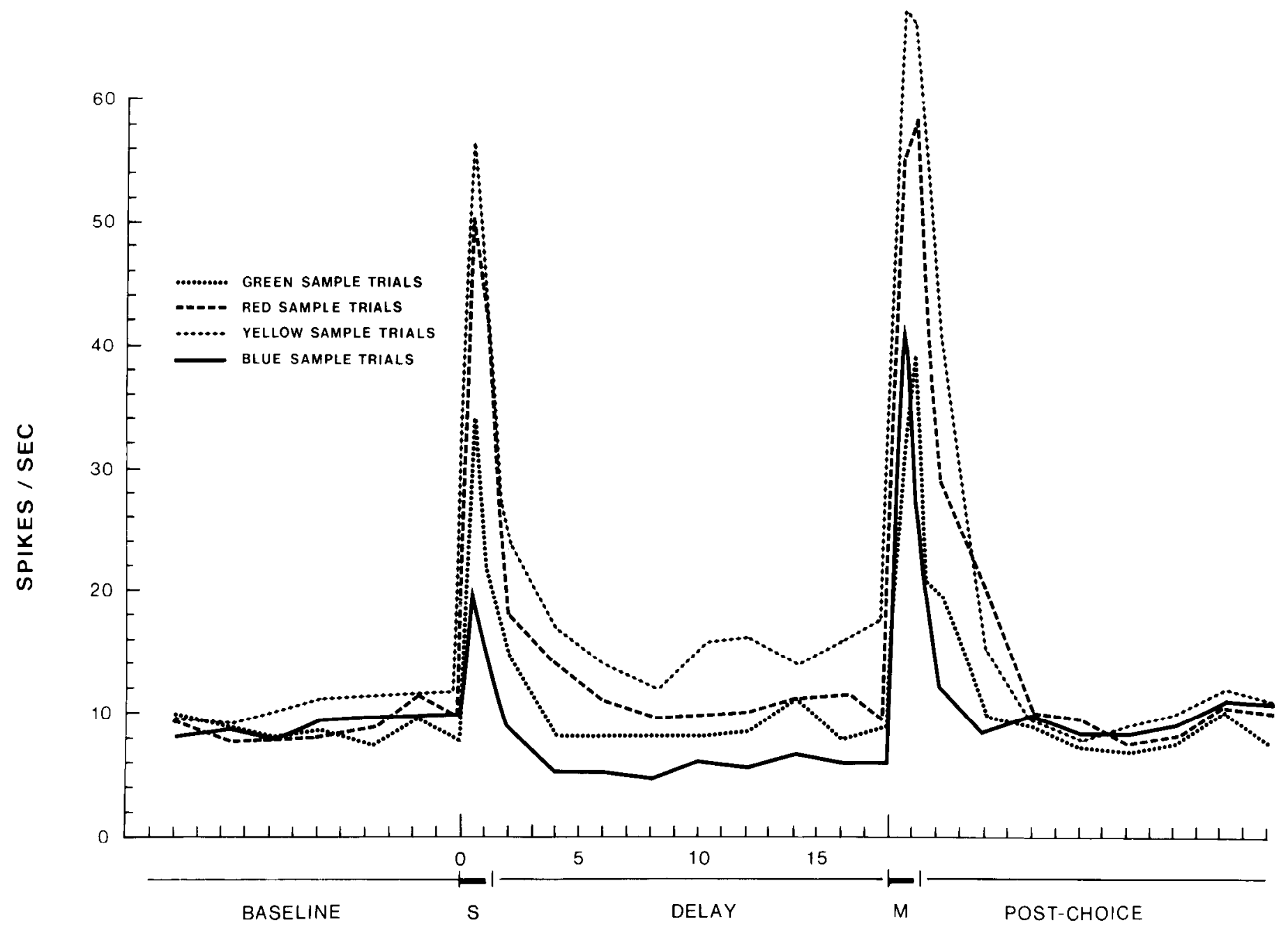

TIME (SEC)

Figure 6. The average firing frequency of a cell (the same cell as in Fig. 4) through the entire length of the DMS trials. Sample $(S)$ and match $(M)$ periods are marked by horizontal bars under the time base. Note the color-related ranking of firing frequencies in sample and match periods as well as during the delay.

and thus, some of the neurons were more active during the delay. In any case, all three interpretations are inadequate for differential delay activation, that is, for color-dependent elevation of firing after the sample.

A plausible view of delay activation is that the cells exhibiting it are involved in short term retention. A few points can be adduced in support of this proposition. First, the activation occurs during that time span which, for correct performance, the animal must bridge with mnemonic retention of the sample. Second, the relationships between delay-activity and performance, however few and difficult to substantiate statistically, point to the functional significance of that activity for sample retention. Third, there is the striking contrast between delay and post-trial discharge: activation, as a rule, terminated with the trial and did not resume after the choice, even though, at the time just preceding the choice, the animal again had to foveate the sample color for correct response (a point also against the afterdischarge hypothesis).
Thus, with the termination of the need to remember the sample, elevated firing likewise came to an end.

On grounds similar to those for sample reactions, it is reasonable to suppose that nondifferential delay-activated cells were involved in the retention of stimulus features that were constant for all samples and trials. Furthermore, it is possible that they also were subject to internal input related to motivation or expectancy of reward. However, in addition to such external and internal factors which our experiments were not designed to sort out, it is evident that the color of the sample determined the activity of some cells during the subsequent delay. Those may have been neurons engaged in temporary memory of color.

Caution is necessary, however, in ascribing to any cell a color-specific memory function. For one thing, the number of tested hues was very limited. Therefore, even units whose firing was clearly and preferentially elevated after a given color could not be assumed to specialize 


\section{S}

DELAY

M

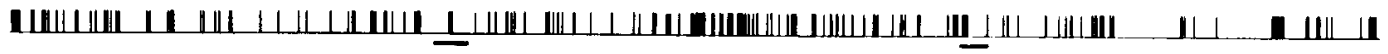

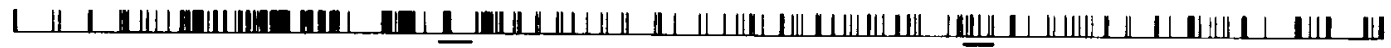

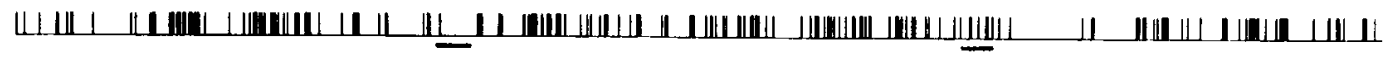

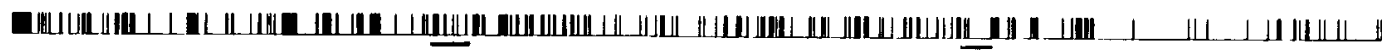

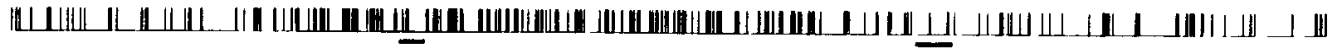

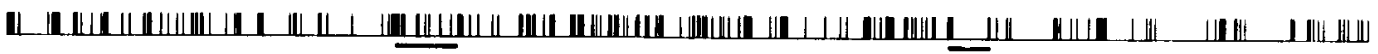

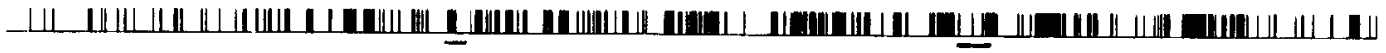

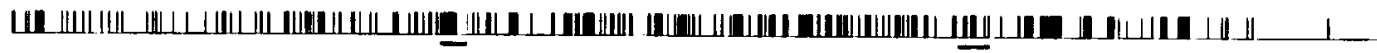

몸
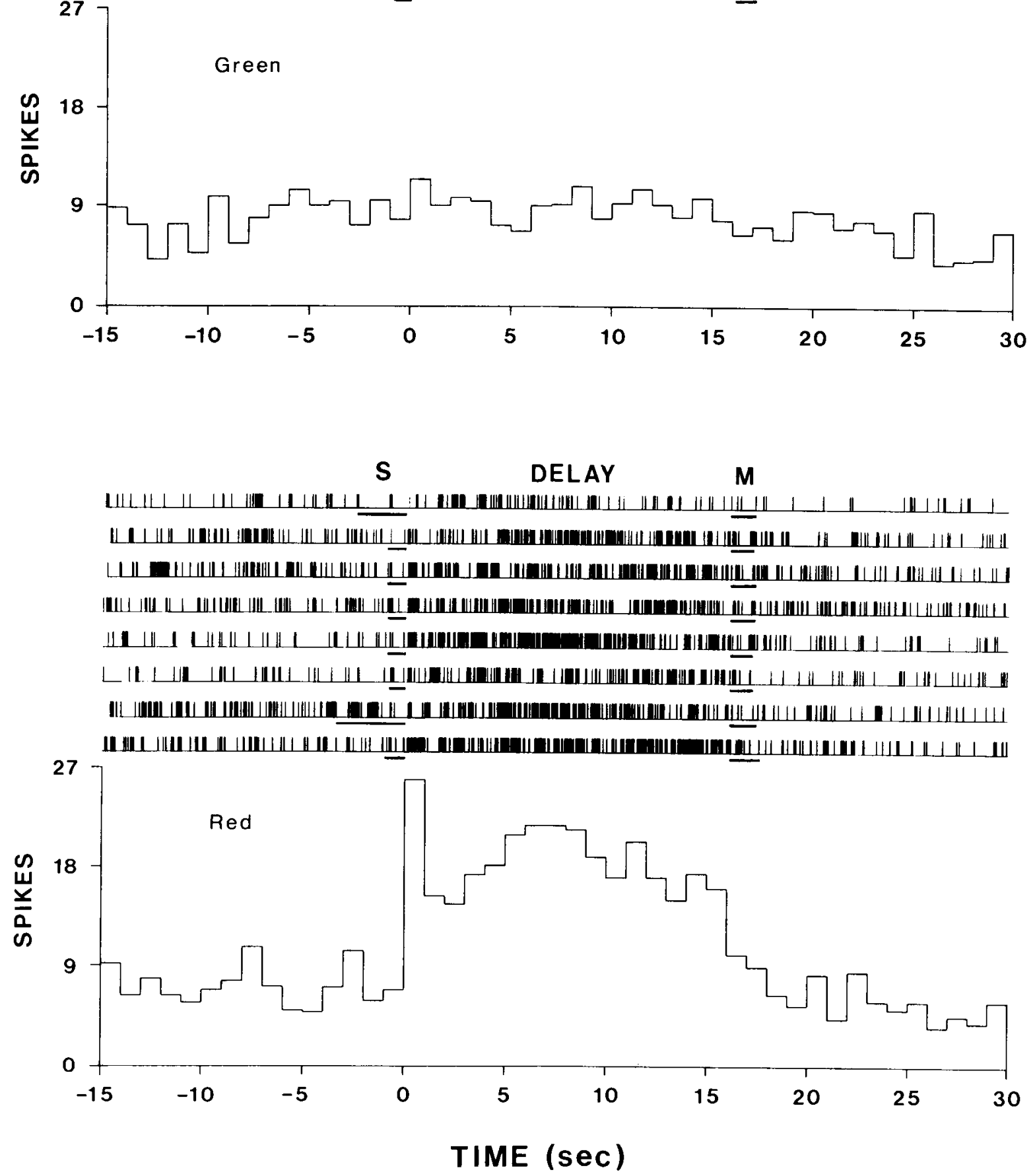

Figure 7. Discharge of a delay differential IT cell during green and red sample trials ( $S$, sample; $M$, match). Frequency histograms are time-locked with the offset of the sample. Note the activation during the delay of the red sample trials. 

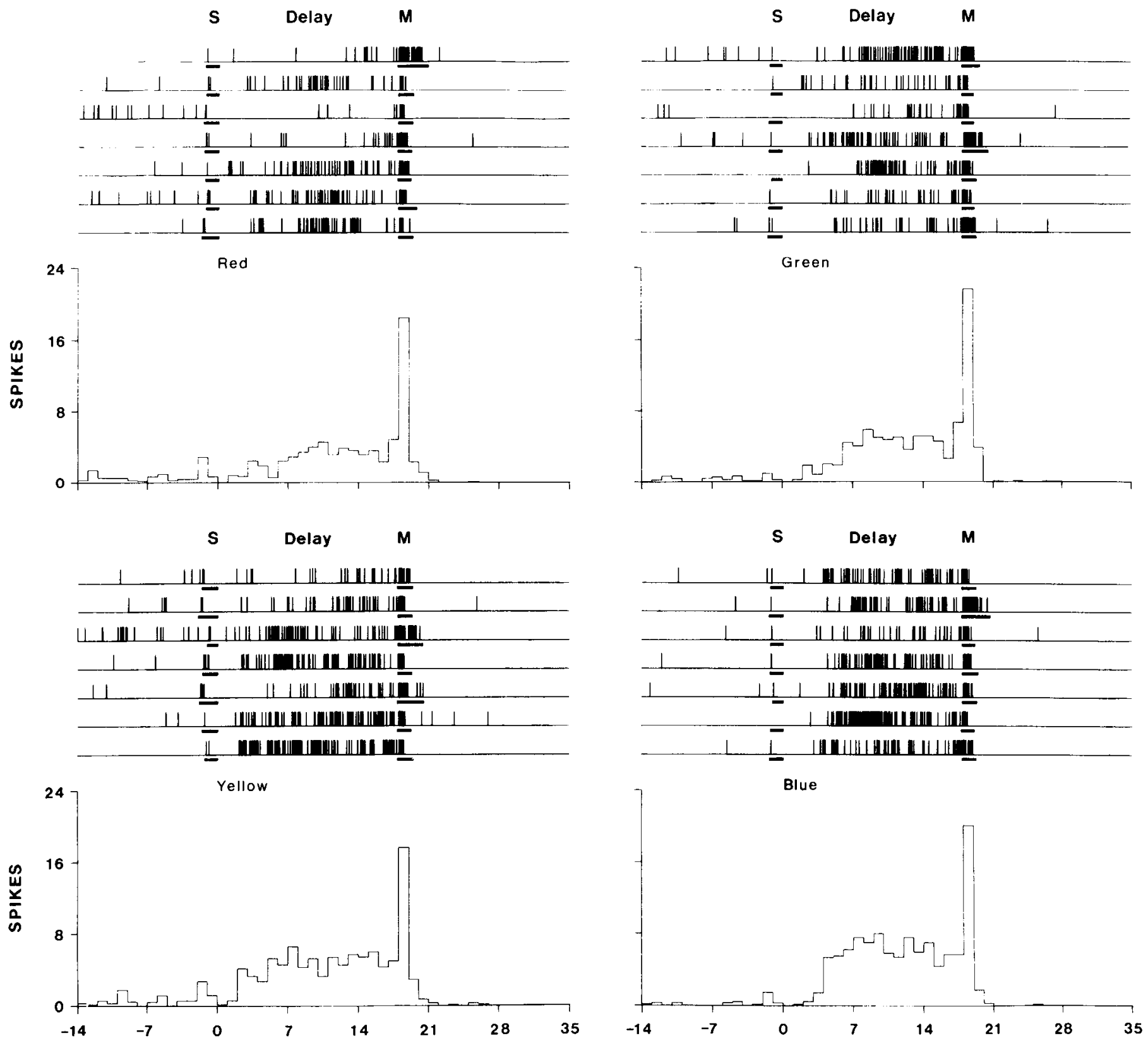

TIME (sec)

Figure 8. Delay-activated IT unit exhibiting minor reactions to the sample $(S)$ and large reactions to the choice $(M$, match) lights.

exclusively in coding or retaining that color. At most, such units can be presumed to participate more than others in the representation and memory of that color and perhaps other features of the sample stimulus as well. That stimulus, by virtue of its various attributes, may be supposed to activate a large pool of IT cells. Subsets of neurons in that pool (e.g., delay differential units) may be especially attuned to a sample color while also reacting to properties deriving from the animal's experience in the task. In other words, even cells that appear engaged in categorical memory of color may be activated by context and therefore may participate in associative memory. In fact, the reaction to color itself may be entirely determined by context (Fuster and Jervey, 1981). This takes us to the logical question: how much of what we see is "pre-wired" and how much is a product of learning? The question could only be answered definitively by recording from the same IT units throughout the learning of the task, which is technically impractical.

The importance of context is underscored by the finding that some units responded more to the sample color when presented alone than as one of the choice colors or vice versa. In this respect, our results are in accord with those obtained by Gross et al. (1979) and Mikami and Kubota (1980) using a task (Konorski task) somewhat 

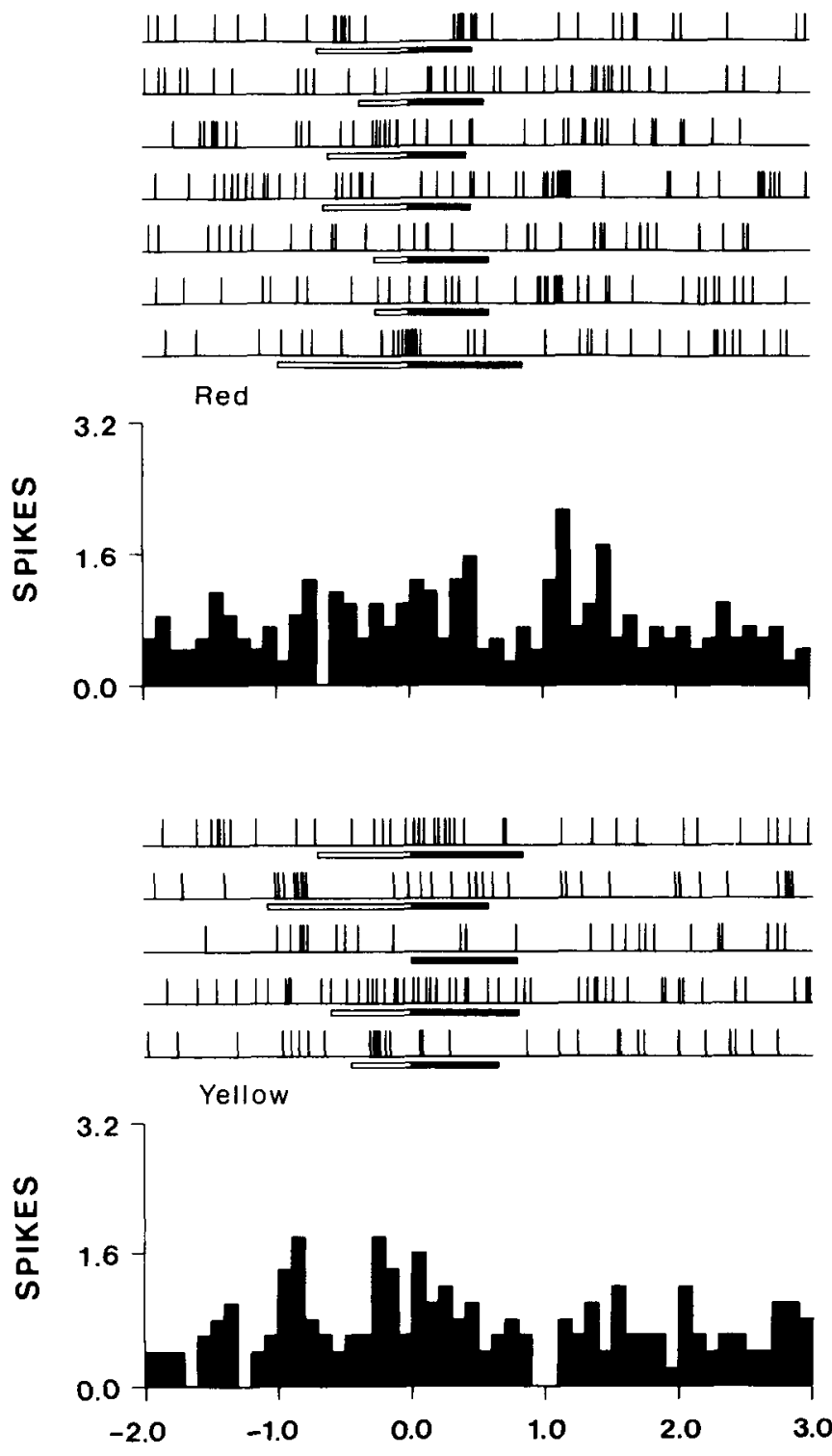

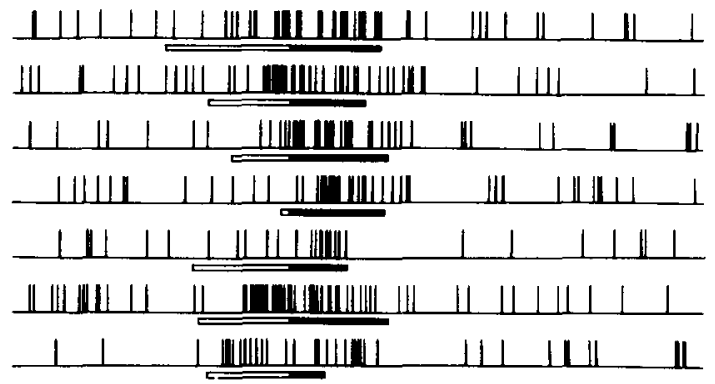

Green

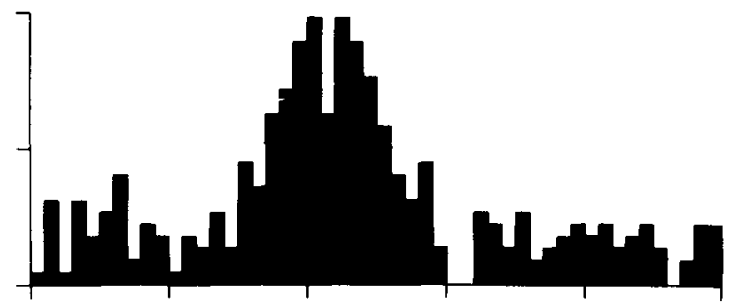

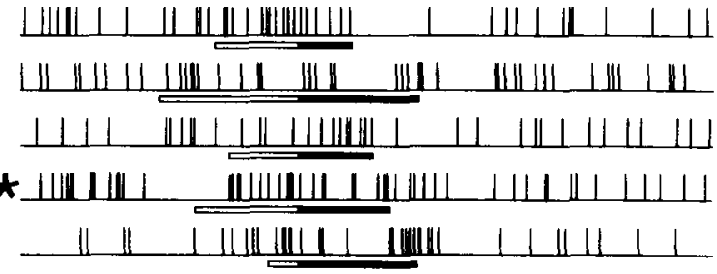

Blue

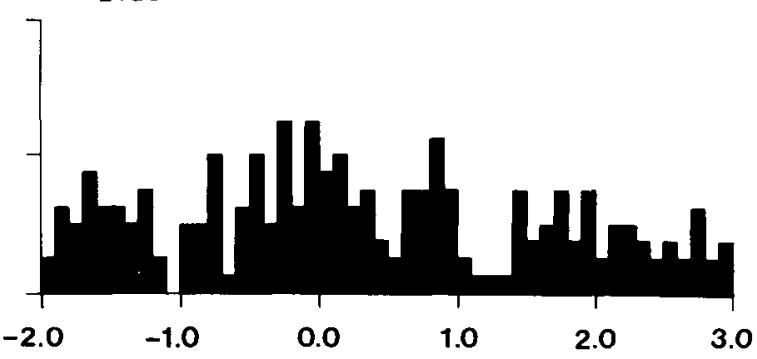

TIME (sec)

\section{Errors}

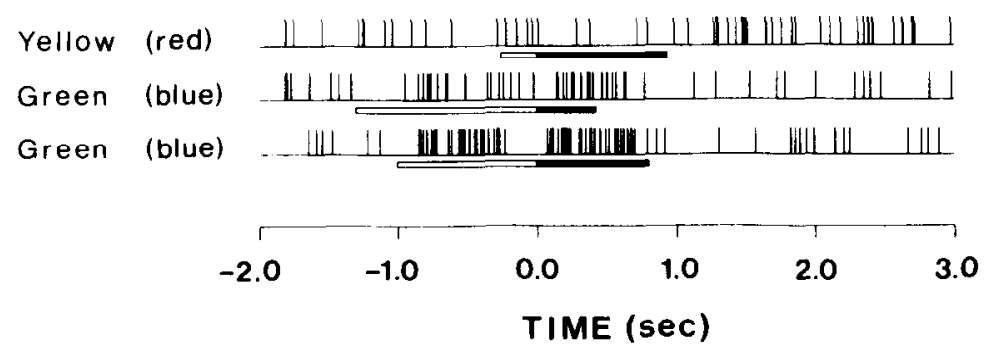

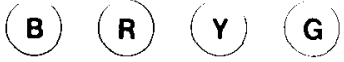

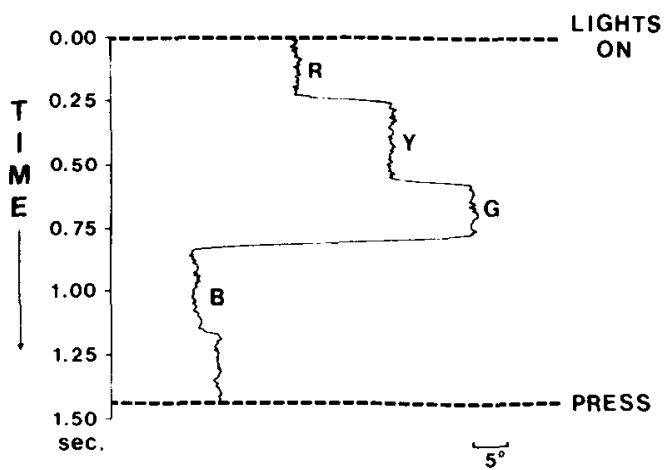

Figure 9. The activity of a cell in the matching period, that is, during exposure to the choice lights (horizontal bars). Histograms are time-locked with ocular fixation on the chosen color (marked by the transition from open to black bar under the individual records). Note the accelerated firing before and during foveation of the green choice light in trials with the green sample. Lower left, record excerpts from three trials ending in the incorrect choice (the chosen colors are indicated at left; in parentheses, the correct sample colors are given). The inset in the lower right corner shows the horizontal EOG during the matching period of the trial marked above with an asterisk. Capital letters indicate the colors of the buttons and the record of ocular fixation of each of them ( $B$, blue; $R$, red; $Y$, yellow; $G$, green). Note that, in that trial, the animal scanned all four buttons before pressing the blue one. 


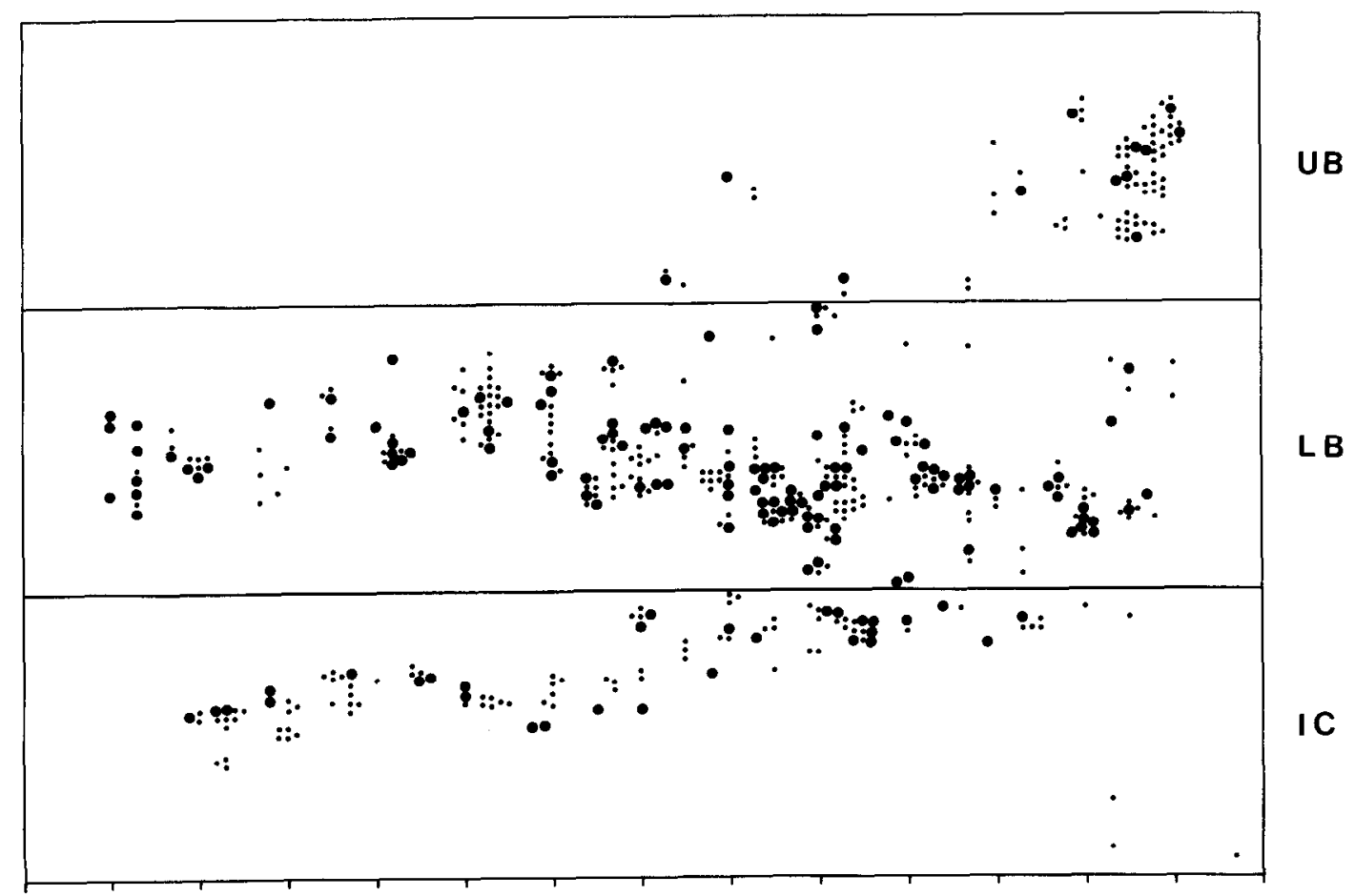

Differential Delay Activity

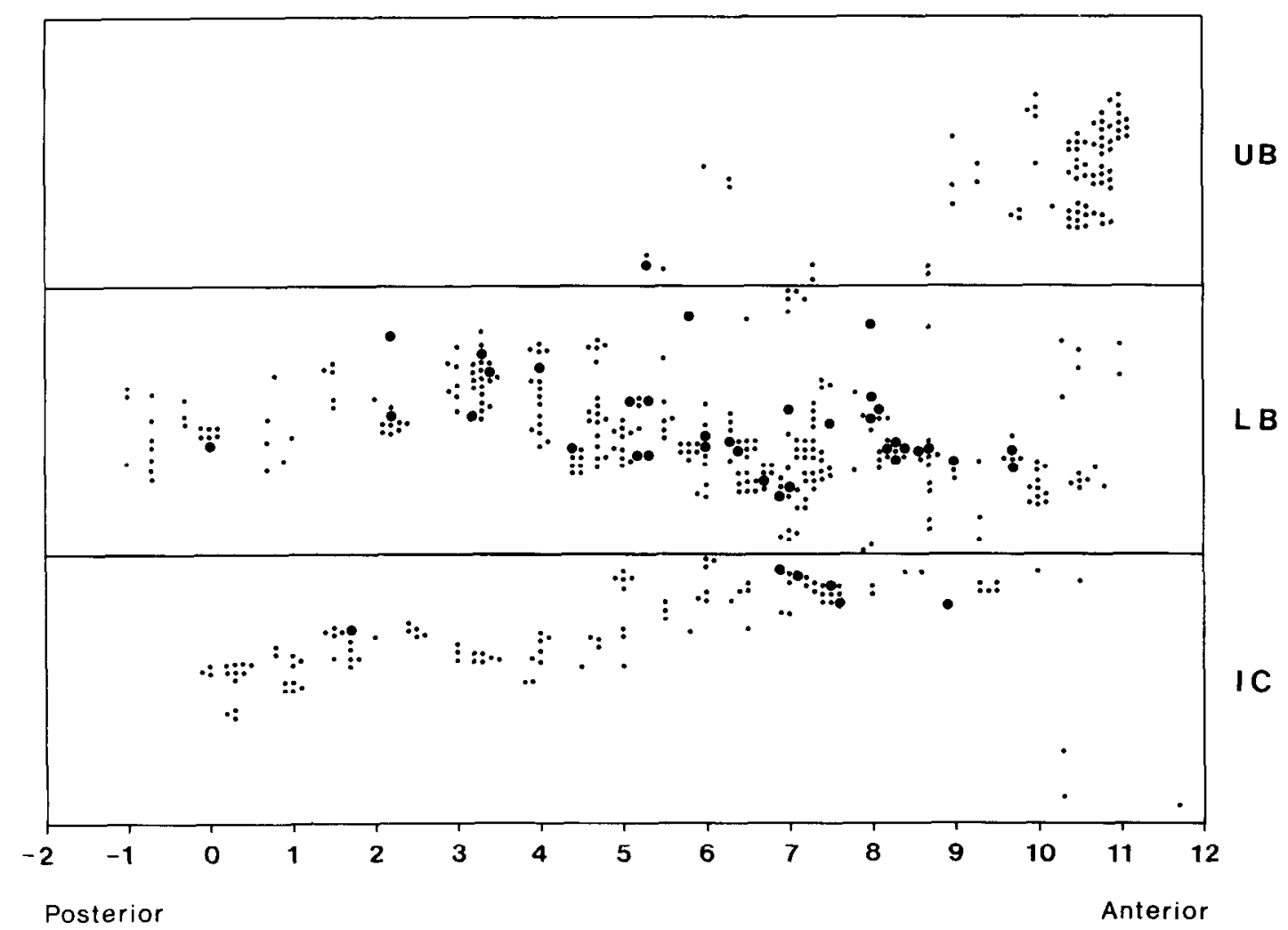

\section{STEREOTAXIC PLANE}

Figure 10. Scatter plots of units showing (above) delay activation (both differential and nondifferential) and (below) delay differential activity only. The two-unit categories are indicated by larger dots against the background display of all of the units investigated in the study. $I C$, Inferior convexity; $L B$, lower bank; $U B$, upper bank. 
similar to ours. They noted different unit reactions to one and the same colored stimulus depending on whether it appeared as the sample or as a stimulus for matching. Neither of those studies, however, provided clear evidence of color-dependent delay activity, perhaps because of the relative brevity of the delays utilized. Another reason may be that both studies were concerned primarily with the cortex of the IT convexity.

Comparing I'T units with prefrontal units in the same task (Rosenkilde et al., 1981; J. M. Fuster, R. H. Bauer, and J. P. Jervey, manuscript in preparation), some general differences become apparent: (1) spontaneous activity is somewhat higher in IT cortex than in prefrontal cortex; (2) more differentiation of colors is found in IT cortex, both in terms of the number of color-dependent units and the magnitude of firing frequency differences; and (3) more post-trial firing changes are seen among prefrontal units than among IT units.

The apparent involvement of IT neurons in visual DMS is fully consistent with observations that, in man (Milner, 1968) and other primates (Stepień et al., 1960; Buffery, 1967; Kovner and Stamm, 1972; Delacour, 1977; Fuster et al., 1981), the functional integrity of the IT cortex is important for the performance of short term memory tasks. Our results are also consistent with those of circumscribed ablations of temporal cortex (Mishkin, 1972; Wilson et al., 1972; Sahgal and Iversen, 1978), leading to the inference that "anterior" IT cortex, which is the cortical region chiefly explored in this study, is especially important for some aspect of visual memory. (Functionally and anatomically, what has been called "posterior IT cortex" is not IT cortex proper but foveal prestriate cortex; Dean, 1976.) However, inasmuch as delay-activated and delay differential units were found more frequently in the cortex of the lower bank than in that of the convexity, our results suggest a functional dissociation of these two parts of IT cortex that lesion studies have not heretofore revealed. If our interpretation of the behavior of those units is correct, our findings may be viewed as pointing to a substantial involvement of sulcal cortex in visual retention. Thus, under conditions such as those of the present experiments, visual information may be analyzed first in the convexity cortex and then provisionally deposited in the cortex of the superior temporal sulcus. At any rate, the suggested progression of processing from convexity to ventral bank of the sulcus follows the direction of demonstrated anatomical pathways (Scltzer and Pandya, 1978; Desimone et al., 1980).

In conclusion, IT neuron populations seem to participate in three major operations required from the monkey in a delayed matching trial: the acquisition, the retention, and the retrieval of visual information. A clear topographic separation of these operations is not possible because many units appear to participate in more than one of them. However, units that mainly or exclusively participate in short term retention seem to be concentrated in the lower bank of the superior temporal sulcus.

The cortical mechanisms at play in the short term memory trial may be essential for the formation of long term memory and, in this respect, the role of IT cortex in visual short term memory may be at the foundation of its well recognized importance for the learning of visual discriminations. Future research should help us under- stand how those mechanisms, which are reflected in the behavior of IT units, help the organism establish permanent representations of the visual world.

\section{References}

Bond, H. W., and P. Ho (1970) Solid miniature silver-silver chloride electrodes for chronic implantation. Electroencephalogr. Clin. Neurophysiol. 28: 206-208.

Braitman, D. J., and W. A. Wilson (1976) Unit activity in the inferotemporal cortex of rhesus monkey during the performance of visual discrimination tasks. Soc. Neurosci. Abstr. 2: 1068.

Buffery, A. W. H. (1967) Learning and memory in baboons with bilateral lesions of frontal or inferotemporal cortex. Nature 214: $1054-1056$.

Chow, K. L. (1951) Effects of partial extirpation of posterior association cortex on visually mediated behavior in monkeys. Comp. Psychol. Monogr. 20: 187-217.

Cowey, A., and C. G. Gross (1970) Effects of foveal prestriate and inferotemporal lesions on visual discrimination by thesus monkeys. Exp. Brain Res. 11: 128-144.

Dean, P. (1976) Effects of inferotemporal lesions on the behavior of monkeys. Psychol. Bull. 83: 41-71.

Delacour, J. (1977) Cortex inférotemporal et mémoire visuelle à court terme chez le singe. Nouvelles données. Exp. Brain Res. 28: 301-310.

Desimone, R., and C. G. Gross (1979) Visual areas in the temporal cortex of the macaque. Brain Res. 178: 363-380.

Desimone, R., J. Fleming, and C. G. Gross (1980) Prestriate afferents to inferior temporal cortex: An HRP study. Brain Res. 184: 41-55.

Fuster, J. M. (1961) Excitation and inhibition of neuronal firing in visual cortex by reticular stimulation. Science 133: 2011-2012.

Fuster, J. M., and J. P. Jervey (1981) Inferotemporal neurons distinguish and retain behaviorally relevant features of visual stimuli. Science 212: 952-955.

Fuster, J. M., A. Herz, and O. D. Creutzfeldt (1965) Interval analysis of cell discharge in spontaneous and optically modulated activity in the visual system. Arch. Ital. Biol. 103: $159-177$.

Fuster, J. M., R. H. Bauer, and J. P. Jervey (1981) Effects of cooling inferotemporal cortex on performance of visual memory tasks. Exp. Neurol. 71: 398-409.

Gross, C. G. (1973) Inferotemporal cortex and vision. In Progress in Physiological Psychology, E. Stellar and .J. M. Sprague, eds., Vol. 5, pp. 77-123, Academic Press, New York.

Gross, C. G., C. E. Rocha-Miranda, and D. B. Bender (1972) Visual properties of neurons in inferotemporal cortex of the macaque. J. Neurophysiol. 35: 96-111.

Gross, C. G., D. B. Bender, and M. Mishkin (1977) Contributions of the corpus callosum and the anterior commissure to visual activation of inferior temporal neurons. Brain Res. 131: 227-239.

Gross, C. G., D. B. Bender, and G. L. Gerstein (1979) Activity of inferior temporal neurons in behaving monkeys. Neuropsychologia 17: 215-229.

Jones, E. G., and T. P. S. Powell (1970) An anatomical study of converging sensory pathways within the cerebral cortex of the monkey. Brain 93: 793-820.

Kovner, R., and J. S. Stamm (1972) Disruption of short-term visual memory by electrical stimulation of inferotemporal cortex in the monkey. J. Comp. Physiol. Psychol. 81: 163-172.

Mikami, A., and K. Kubota (1980) Inferotemporal neuron activities and color discrimination with delay. Brain Res. 182: 65-78.

Milner, B. (1968) Visual recognition and recall after right temporal-lobe excision in man. Neuropsychologia 6: 191-209. 
Mishkin, M. (1972) Cortical visual areas and their interactions. In Brain and Human Behavior, A. G. Karczmar and J. C. Eccles, eds., pp. 187-208, Springer, New York.

Moss, M., H. Mahut, and S. Zola-Morgan (1981) Concurrent discrimination learning of monkeys after hippocampal, entorhinal, or fornix lesions. J. Neurosci. 1: 227-240.

Ridley, R. M., N. S. Hester, and G. Ettlinger (1977) Stimulusand response-dependent units from the occipital and temporal lobes of the unanaesthetized monkey performing learnt visual tasks. Exp. Brain Res. 27: 539-552.

Rocha-Miranda, C. E., D. B. Bender, C. G. Gross, and M. Mishkin (1975) Visual activation of neurons in inferotemporal cortex depends on striate cortex and forebrain commissures. J. Neurophysiol. 38: 475-491.

Rolls, E. T., S. J. Judge, and M. K. Sanghera (1977) Activity of neurones in the inferotemporal cortex of the alert monkey. Brain Res. 130: 229-238.

Rosenkilde, C. E., R. H. Bauer, and J. M. Fuster (1981) Single cell activity in ventral prefrontal cortex of behaving monkeys. Brain Res. 209: 375-394.
Sahgal, A., and S. D. Iversen (1978) Categorization and retrieval after selective inferotemporal lesions in monkeys. Brain Res. 146: 341-350.

Sato, T., T. Kawamura, and E. Iwai (1980) Responsiveness of inferotemporal single units to visual pattern stimuli in monkeys performing discrimination. Exp. Brain Res. 38: 313-319.

Seltzer, B., and D. N. Pandya (1978) Afferent cortical connections and architectonics of the superior temporal sulcus and surrounding cortex in the rhesus monkey. Brain Res. 149: $1-24$.

Stepień, L. S., J. P. Cordeau, and T. Rasmussen (1960) The effect of temporal lobe and hippocampal lesions on auditory and visual recent memory in monkeys. Brain 83: 470-489.

Von Bonin, G., and P. Bailey (1947) The Neocortex of Macaca mulatta, University of Illinois Press, Urbana, IL.

Wilson, M., H. M. Kaufman, R. E. Zieler, and J. P. Lieb (1972) Visual identification and memory in monkeys with circumscribed inferotemporal lesions. J. Comp. Physiol. Psychol. 78: 173-183. 